\title{
Transmitting intended and suggested routes in ship operations: cognitive off-loading by placing knowledge in the world
}

\author{
Thomas Porathe \\ Department of Shipping and Marine Technology, Human Factors Group, Chalmers University of Technology, SE- \\ 41296 Gothenburg, Sweden. E-mail: thomas.porathe@chalmers.se
}

\begin{abstract}
Transmission of intended and suggested routes to and from electronic chart systems has been identified as a user need. The idea was discussed during a focus group meeting and two field studies in fringe fields like search and rescue (SAR) and ice breaking. A prototype test was then conducted during a SAR drill. The features were very well received by all the participants in the drill. A system simulation with two ships and a VTS station was also conducted in a full mission bridge simulator. Preliminary results are very promising. Behavior with vessels in conflicting situations suggested that the intended routes could facilitate understanding when negotiating with or without VHF communication. No major concerns were expressed by the professional crew members that participated.
\end{abstract}

Keywords: Electronic chart, ECDIS, intended route, suggested route, route planning, route exchange

\section{Introduction}

One of the significant traits of the human spices is our ability to use external cognitive tools to enhance our thinking. The greatest of these tools are undoubtedly language and writing. Using language we can share our thoughts and by distributed effort we can be smarter than alone. By being able to write down what is on our mind, we can relieve our brains from the burden of remembering and off-load our limited and vulnerable working memory [4].

In the maritime domain, knowledge of routes, winds, navigable waters, etc. set high strains on the memory of seafarers. In the beginning coastal travel could be supported by constantly changing local pilots that were picked up and dropped off. Soon such route knowledge began to be recorded in sailing directions, at first only listing pilot changing stations and the distances between then but later also describing courses and dangers. But it was not until the 1700 's the nautical chart started to become common goods onboard ships [1]. The chart opened new possibilities of traveling along other routs than the old sailing directions described, and also explicitly dem- onstrated uncharted areas. New knowledge could be added to the chart by a distributed effort of the whole maritime community. The chart could be seen both as a repository of more knowledge that any single man could have in his mind and, thanks to Mercator, a computational artifact in which strait lines have a special meaning: they are lines of constant compass direction. Edwin Hutchins called the chart a crystallization of practice into a physical artifact [2].

As a rout planning instrument many generations of bridge officers have gathered around the nautical chart to plan the upcoming voyage. By pointing to the chart some certainty could be established of a common reference frame and the effects of e.g. different wind conditions could be simulated in the minds of the planners. Finally the details of the planned voyage would be confirmed by the pencil line depicting the intended track from one port to the other. The line on the chart served as confirmation of a mutually agreed sailing plan and had to be approved by the master. It also served as cognitive offloading for the Officer of the Watch, as he did not need to remember exact path of the voyage ahead. At regulated intervals he would confirm his position by 
observations of the world (cross bearings, astronomical observations, radar range and bearings, etc.) and plot these positions into the chart as a fix constituting one position on the factual route sailed. These fixes could then be compared to the intended route and course corrections made when needed.

By this system of planned and sailed track a record of past, present and future could be held giving the watch officer a good instrument for decision making.

Also in modern electronic chart systems, the so called Electronic Chart and Display Information Systems (ECDIS) the same principle is present. Global satellite systems are used to position a symbol depicting the own ships present position on an electronic map. At regular intervals the position is saved to a memory and a line constituting the past, the historic track can be displayed. Before the departure the captain of any commercial ship is responsible for that the waypoints of the upcoming voyage has been added to the chart computer representing the complete intended route from port to port.

A complicating factor in navigation is the presence of other ships on the seas. This brings a certain amount of uncertainty into the voyage plan. Maybe it will not be possible to follow the plan in all details due to conflicting situations to other ships.

Using the Automatic Information System (AIS) ships now a day also transmits their present position at regular intervals, along with information of speed, turn rate, name, cargo, and destination. This information can be received by ships within radio range and is picked up by land stations or satellites. All ships positions are recorded by most coastal states and the historic track of these ships can be visualized on request.

The AIS system has become mandatory for commercial vessels over a certain size and is of great importance. It gives the unidentified radar echo a name and a destination. The presence of a name opens for the ability to call the ship on radio, instead of just calling "Ship on my starboard," when there might be many ships to starboard. The destination tag in the AIS information gives a clue of the intended route the ship - maybe - because if the destination is Brazilian Recife it might not always shed much light on the intentions in the Sound between Sweden and Denmark.

However, in the navigation computer of every ship resides a detailed voyage plan for the entire trip. It is technically feasible to transmit not only the present position though the AIS, but also a number of future waypoints constituting the intended route. The positive outcomes of such a feature are obvious: to avoid catastrophic misunderstanding of each other's intention. But the crucial question for this study is what might be the unintended consequences of such a feature?

\section{Method}

\subsection{Collecting user needs}

\section{Focus group}

During a focus group 9 December 2010 with 10 experienced Swedish, Danish and Finnish master mariners the usefulness and risks of sending intended routes was discussed. The result from the discussion was that the pros were obvious if the ambiguity of the intentions of a vessel in the vicinity could be removed. A possible risk was that a ship would display one intention but then not follow it; much like a car would use its turn signal but then instead of turning go straight and thereby cause an accident.

Another benefit would be that Vessel Traffic Services and pilots easily could detect in advance if a ship had the intentions of going on the wrong side of a buoy and thereby risk grounding. They could then call up and warn the ship in question or even better, send out a suggested route, avoiding the danger. The ship could then either click "accept", adding the new route to its active route, or dismiss the suggestion by clicking "reject".

\section{Field study on icebreaker}

During a field study onboard the Swedish icebreaker Frej in the Bay of Bonita in 5-8 April 2011 another user need was noted. During a winter the ice shield is drifting back and forward between Finland and Sweden depending on the prevailing winds. Sometimes the wind press is hard and ice ridges are created. These ridges can be hard even for the huge icebreakers to pass. Therefore the job of breaking ice is not one of keeping a straight course through the ice but one of visually by eye, ice radar and experience finding the most easy tracks trough the ice. Often these tracks become quite winding channels. Once the icebreaker has passed the crushed ice will float back and cover the channel behind the breaker and make it difficult to spot. (See Figure 1.) 


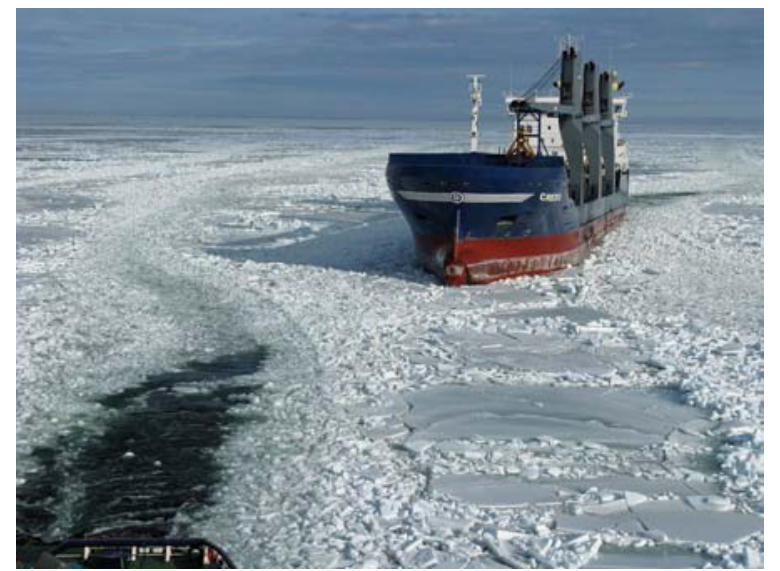

Fig. 1. The icebreaker Frej assisting a ship stuck in the ice. Note how the channel "disappears" behind the stern of the icebreaker.

The job of the ice breakers is to assist ships through the ice to ports in the north of Sweden and Finland. They do that by fetching the ship at the ice front or by relieving another icebreaker and then go in front of the single ship, or more often, in front of a convoy of ships. If the ice is very sever and the assisted ship has weak engine power the icebreaker may have to connect tug lines.

For the ice breaker it is most efficient to use a channel that has already been broken up. However, by the end of a year the ice shield is full of channels that was broken but has frozen solid again. And it is very difficult to see the difference between an open channel and a frozen one. As an aid to find the open channel the icebreakers can use their electronic chart system to call up the historic track from themselves, another icebreaker or any other ship that recently passed through the ice. These are the historic AIS tracks saved in the database of the particular Adveto ECDIS system used by the Swedish icebreakers. These historic tracks are based on a graphic path and do not contain waypoints as sailing tracks do. Adveto is not common on foreign ships so the method cannot be copied by ships that do not have this Adveto system. Taking into consideration that the ice is constantly moving the value of such an historic track can last from hours to days depending on the wind conditions, but never the less this is valuable information that allows the icebreaker to find the open track with a minimum of effort. One of the bridge officers onboard Frej even said: "The day they take away the Adveto system I will quit this job."

Having to go and fetch all but the most powerful ships can make the job of an icebreaker very inefficient and at times ships have to wait for assistance, stuck in the ice, for several days. A user need that was expressed by the bridge officers onboard Frej was the ability to cut out a relevant snippet of some icebreaker or other ships historic track, change it into an high density waypoint track and send it addressed to a particular ship so that they could amend it to their active track and find the open ice channel by themselves. In that way, the bridge officers said, the icebreaker could park in the middle of their area and function as a traffic center and only need to fetch the most vulnerable ships.

The user need expressed by the bridge officers of the icebreaker Frey should be technically feasible using the same methods as the route exchange discussed earlier.

Field study during a sea search and rescue operation Another field study was conducted in 19-20 March 2011 during a training exercise with the volunteer Swedish Sea Rescue Society (SSRS) in the waters between Hano and Horvik in the southern part of Sweden. The SSRS had for several days been training five local rescue stations and on the last night there was a rescue drill planned. At 2 o'clock in the morning an alarm came saying that two small boats with teenagers coming from a party on the island of Hano never arrived to Horvik as planned. Units from the five rescue stations were called in to search. A search area was designated by the joint rescue coordinator and as On-Scene Commander (OSC) the larger rescue cruiser was designated. The OSC now had the choice of dividing the search area between the five units to his disposal or to do a joint search. The first alternative would mean to designate a search polygon to each unit and let that unit plan a parallel search pattern within that area, or even plan the parallel search pattern and send it to the unit. Such a transmission of coordinates would have to be made over VHF and entered into the ECDIS of the unit using keyboard. But many of these units were small, open RIB boats with very limited abilities of keying anything into the chart computer due both to exposure; motion and primitive on screen keyboards (see Figure 2). 


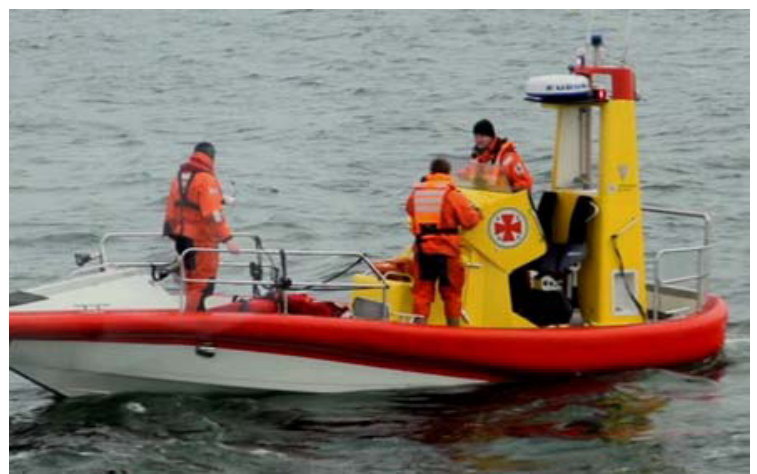

Fig. 2. An open ridged inflatable boat in the Swedish Sea Rescue Services organization.

So even if the first option would be the best the practical solution most often is to do what is called a fork search: the OSC holds a course in the middle and all the other units one, two and three cables out on starboard and port beam.

The SSRS personal that was interviewed expressed a need for the ability to send readymade search polygons and patterns from OSC directly to each individual search unit, or to any ship equipped with an ECDIS participating in the search.

This user need would be technically feasible using the same technique as described earlier.

\subsection{Prototype testing in a SAR drill}

A prototype ECDIS test application called ee-INS with the abilities to send and receive tracks was then developed by the Danish Maritime Safety Administration together with the Maritime Human Factors Group of Chalmers University of Technology in the EU Inter regional IVB Baltic Sea EfficienSea program. To test the ability to send and receive tracks an invitation to participate in a Danish search and rescue drill in the Great Belt outside Nyborg 27-28 May 2011 was accepted. In eastern Denmark the search and rescue units are navy ships belonging to the Danish Marine Home Guard. They are all relatively large and of the same type (see Figure 3).

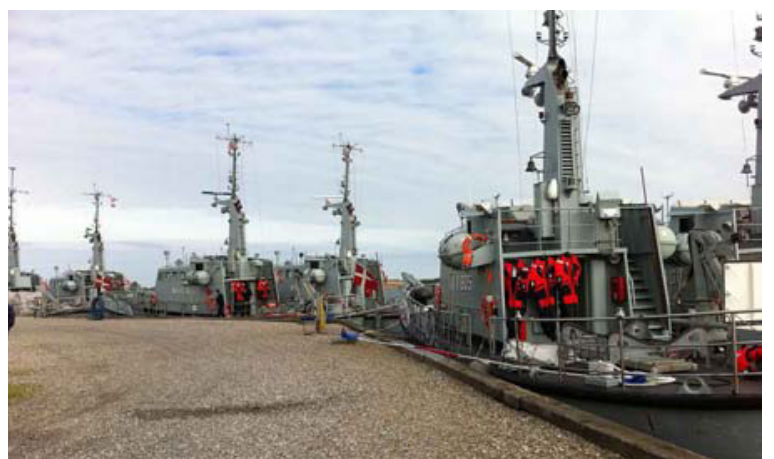

Fig. 3. Search and rescue boats from the Danish Marine Home Guard.

The test equipment was installed in three of the ships and on one AIS transmitter mast form the Danish Maritime Safety Administration. The mast was used to transmit the AIS binary messages necessary that made the system work. This is not the place for a thorough technical description of the system. Such description will in due time be published in the output from the EfficienSea project (http://www.efficiensea.eu).

A laptop containing the ee-INS software was placed on the back bridge of the three units, one of which was the OSC and housed the exercise command. The ee-INS was not allowed to be used for real navigation because the volunteer crew was supposed to train on their regular equipment, but when there was spare time we were allowed to demonstrate the functionality of the prototype system and gather comments and impressions.

When the exercise started the OSC designated a search area to each unit. This search area was transmitted using VHF radio in spoken voice transmitting 4 coordinates containing longitude and latitude (the words "north" and "east" and two times six digits). These coordinates were then received onboard each unit and was written down on a piece of paper by the radio operator. This piece of paper was then handed to the navigation officer at the front of the bridge who started to program the ships ECDIS system. Clicking through different menus and finally entering the same 12 numbers the search area finally appeared on the ECDIS. On the observation video this process, from start of the VHF transmission until the search area appeared on the ECDIS screen, took 14 minutes. The whole time the search polygon was present on the ee-INS screen, sent in the same time the VHF transmission started (see Figure 4). 


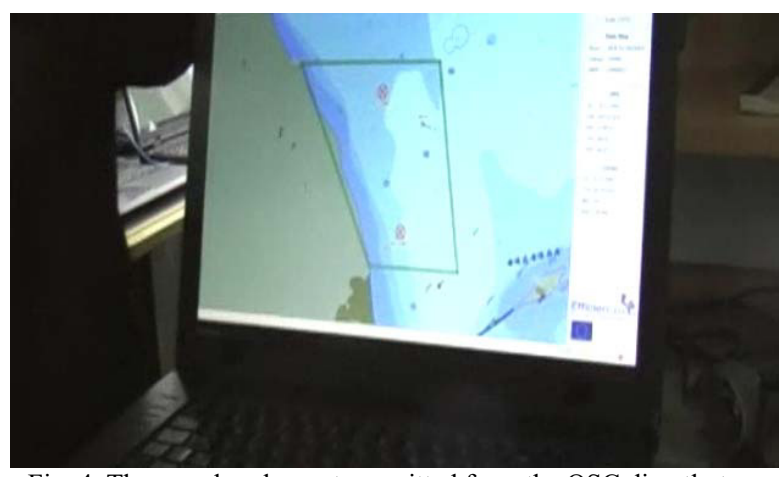

Fig. 4. The search polygon transmitted from the OSC directly to the prototype system.

For a professional and trained crew this process had probably gone a lot faster, but using volunteer crews with limited time for training is the reality for many sea rescue services around the world and even with a trained crew the risk of misinterpreting a number transmitted in voice and in hand writing still remains. The transmission through the AIS binary messages on the ee-INS was produce by a graphical interface on the OSC ship and was instantly presented on the unit it was addressed to.

After the three test units had received their search polygons and programmed in their search pattern in the standard ECDIS of the ship, the navigator once again entered the search pattern in an approximate way on the ee-INS, right clicked and chose "active route" in the menu. As the route was made active it was immediately broadcasted to all ships in the vicinity with an ee-INS and would be visible if the configuration "show intended routes" was activated. This way the OSC got immediate feedback of the intentions of the three units equipped with ee-INS.

The exercise management was so happy with the prototype system that they moved their primary command and control interface from the paper chart to the ee-INS to monitor the drill.

In the debriefing that took place a couple of days later the ee-INS system and the ability to send and receive intended routes got appraisals from the exercise command and the participating crews that had come in contact with the system.

\subsection{Simulator test}

On order to test route exchange in a normal traffic environment a simulator study was conducted at the full mission bridge simulators at the department of Shipping and Marine Technology at Chalmers Uni- versity of Technology in on 1 September 2011. The bridge simulator was set up with two ships in the Sound between Sweden and Denmark, an area with relatively high traffic density. Together with the two live ships a large number of target ships were used (ships that run on a predefined path but can be manually manipulated by the simulator instructor to trigger situations etc.) The traffic pattern was based on actual traffic in the Sound recorded from AIS data between 18 and 19 January 2009.

The method used was "system simulation" [3], with the meaning that not only ship based actors take part but also shore based actor like pilots and VTS to further simulate the complexity of a traffic environment in confined waters. In this case a VTS station was used manned by a professional sound VTS operator. Each of the two bridges was manned by a professional captain and a Sound pilot; all with extensive experience of navigating the Sound (see Figure 5).

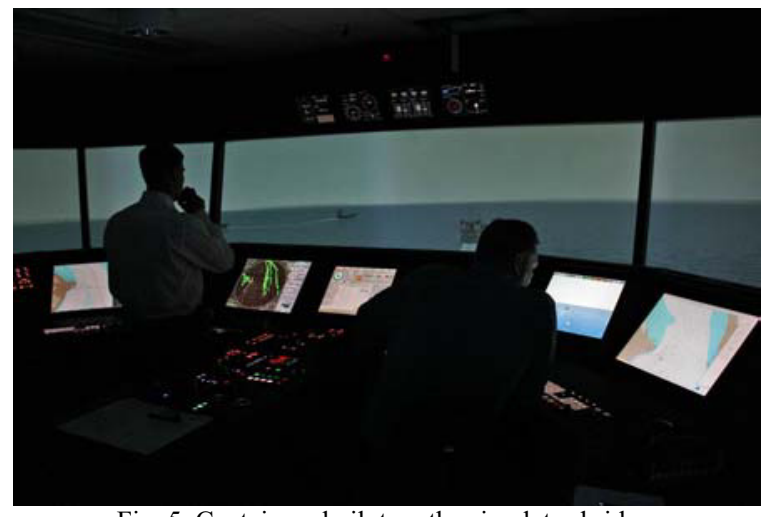

Fig. 5. Captain and pilot on the simulator bridge.

On each of the bridges and in the VTS station a researcher/observer took notes and asked questions, the movement of ships and VHF communication was recorded and the data collected in VSL Site Observer TM software for further analyses. This analysis is not jet finished so the findings presented here are preliminary and based on a limited number of observation protocols.

\section{Results}

\subsection{Simulator test}

As mentioned above the simulator test has not yet been finally analyzed and these are just some preliminary comments based on observations from the 
inary comments based on observations from the simulator control room.

However no really alarming behavior was detected by the involved ships and in several situations the ability to see the other ships intended routes facilitated the negotiations for a solution of conflicting situations. One example will be given here.

The tank ship T.C. Gleisner was southbound in the Sound and was approaching the narrows at the ferry crossing between Helsingborg and Helsingor. Several ferries cross the Sound here every hour and they might suddenly appear from the two ports on either side.

According to the International Regulations for Preventing Collisions at Sea (COLREGS) ship should give way for other ships on their starboard side. But because of the narrow strait the ferries normally give way for all through going traffic or delay their departure to fit an opening in the traffic flow. This is however a behavior that has no support in COLREGS and may cause misunderstanding.

When T.C. Gleisner was approaching the ferry crossing the ferry Tycko Brahe was departing from Helsingor, on the tankers starboard side. The ferry broadcasted her intended route, clearly showing her intention to make a port turn once outside the pier head and pass aft of T.C. Gleisner although she was the stand-on ship. The intended route of Tycko Brahe (see Figure 6) clarified her intentions and explained the sudden port turn in front of T.C. Gleisner.

It seems from a preliminary overview of the results of the simulation that the transmission of intended routes can serve as the unambiguous base for a negotiation also added with VHF communication. Subjects were happy with the tool. The only concern raised was that in very tight and time constrained collision situations none of the ships will have time to click intentions into the ECDIS.

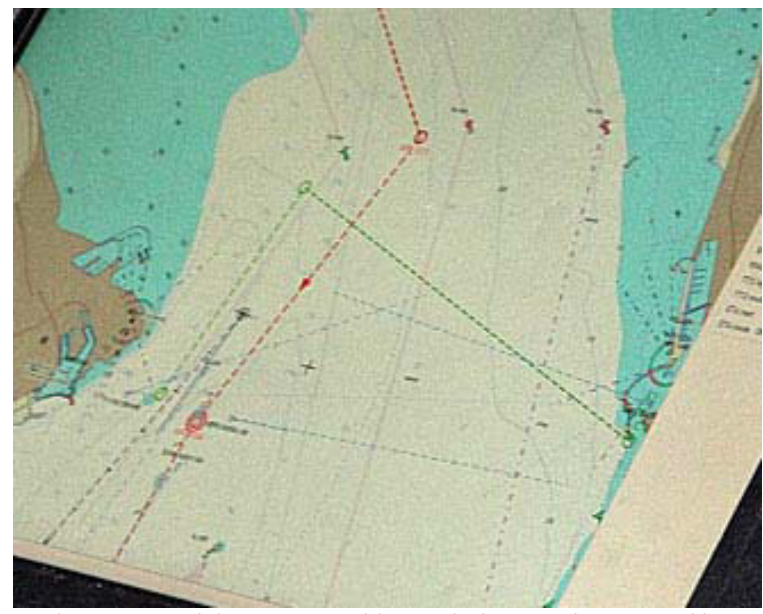

Fig. 6. T.C. Gleisner's own ship symbol somewhat west of her (red) track. Tycko Brahes green track shows she intends to go astern of T.C. Gleisner.

\section{Conclusions}

In three investigations user needs for intended and suggested routes has been found. The effects of using intended and suggested routes have also been studied in two studies. The results are very promising so far but further studies need to be conducted in order to make sure that no unintended consequence of this facility passes unnoticed.

\section{Acknowledgement}

The research presented here has been produced within the EU Inter Regional Baltic Sea program EfficienSea which is gratefully acknowledged.

\section{References}

[1] C. Cotter. Coastal Views in the Development of the Nautical Chart. The Hydrographic Journal, 17 (1980), 7-11.

[2] E. Hutchins, Cognition in the wild. MIT Press, Cambridge, 1995.

[3] M. Lützhöft, T. Porathe, J. Jenvald and J. Dahman. System Simulations for Safety. In O.Turans, J. Bos, J. Stark \& J. L. Colwell (Eds.) Proceedings of the International Conference on Human Performance at Sea 2010. Glasgow: University of Strathclyde, p. 3.

[4] C. Ware, Information visualization: Perception for design, CA: Morgan Kaufman, Elsevier, San Francisco, 2004. 